\title{
RETALT_TPS design and manufacturing
}

\author{
Sofia Paixão ${ }^{1}\left[\right.$ Cláudia Peixoto $^{1} \cdot$ Marta Reinas $^{1} \cdot$ João Carvalho ${ }^{1}$
}

Received: 8 July 2021 / Revised: 17 December 2021 / Accepted: 17 December 2021 / Published online: 8 January 2022

(c) The Author(s) 2022

\begin{abstract}
The present document discusses the development of a new trowelable Thermal Protection System (TPS), able of being mixed, applied and cured directly onto the vehicle structure, with the aim to fulfill the requirements of the thermal properties for the re-usable launch vehicle studied in the Retro Propulsion Landing Technology (RETALT) project. During the development of this TPS, several formula optimizations were made to improve or eliminate cracks in the char surface, increase char stiffness, rheological adjustments, and adhesion improvement to different substrates. The most promising material developed is composed by cork and epoxy resin, together with a set of rheological and thermal resistance additives, that makes it possible to be applied with a spatula, while at the same time it is able to withstand the demanding environmental conditions during atmospheric reentry. In terms of thermal properties, the developed material has a higher thermal conductivity than the current P50 TPS commercialized by Amorim Cork Composites (ACC), but it has a better behavior when exposed to flame conditions. It is expected that the absence of cracks improves its structure and resistance to demanding conditions. The development work included a detailed study of the composition and processes required for the development of a TPS material, which were evaluated by several types of flame characterization tests and thermal properties analysis.
\end{abstract}

Keywords TPS $\cdot$ In situ $\cdot$ Cork $\cdot$ Char $\cdot$ RETALT $\cdot$ P50 $\cdot$ Trowelable

$\begin{array}{ll}\text { Abbreviations } \\ \text { TPS } & \text { Thermal protection system } \\ \text { ACC } & \text { Amorim cork composites, SA } \\ \text { NASA } & \begin{array}{l}\text { National Aeronautics and Space } \\ \text { Administration }\end{array} \\ \text { TGA } & \begin{array}{l}\text { Thermogravimetric analysis } \\ \text { CMC }\end{array} \\ \text { Ceramic matrix composites } \\ \text { RETALT } & \begin{array}{l}\text { RETro propulsion-assisted landing } \\ \text { technologies }\end{array} \\ \text { TRL } & \text { Technology readiness levels }\end{array}$

\section{Introduction}

The objective of a Thermal Protection Systems (TPS) is to minimize the conduction of heat from the external surfaces to the inside of the spacecraft, during ascent and reentry. In addition, an efficient TPS should be able to provide

Sofia Paixão

sofia.paixao@amorim.com

1 Amorim Cork Composites (ACC), Rua Comendador Américo Ferreira Amorim, 260, 4535-186 Mozelos VFR, Portugal mechanical and thermal stability to the space vehicle without compromising weight $[1,2]$.

During the last years, many new TPS materials have been developed and patented, for example, by NASA, United Technologies Corporation, Astrium, among others. High-performance composites such as carbon/carbon composites or ceramic matrix composites (CMC) have been used because of their high thermal resistance and physical properties; however, most of these composite materials are very energy intensive in their production, leading to high manufacturing costs and, most of the time, difficult system integration together with higher weights [1-4].

In this context, the search for new materials, capable of withstand demanding conditions while being at the same time lighter and more cost effective, is carried out all over the world. In this search, silicone, phenolic and epoxy are the main resins chosen, and different fillers and components are combined to create the final product, which results from different productive processes, as impregnation, spraying, agglomeration, trowelability, among others [4-9].

When lightweight materials with excellent thermal performance are desired, cork appears as an immediate option, due to its set of properties, along with the advantage of being a bio-based and sustainable material. Cork is the bark of 
the cork oak tree, a natural closed cell foam with unique properties suitable for aerospace applications such as the excellent thermal insulation, lightweight, good flexibility, and relative low cost. This closed cell structure, and therefore the gas enclosed in cells, allows the material to have a low thermal conductivity, besides a reduction of the heat transfer by radiation through the repeated absorption and reflection [10]. The application of renewable materials in aerospace industry receives a growing interest because of its lower environmental impact when compared to the current state of the art composed of carbon or ceramic composite parts. It should be mentioned that cork has been used since the beginning of the space age (Fig. 1) [6, 10-14].

Currently, cork TPS materials available on the market are mainly produced in form of flat sheets of different thicknesses. Therefore, when complex surfaces are present the material needs to be machined [1].

In the frame of the RETALT project, the main objective is to develop and evaluate the potential application of an in situ cork-based thermal protection system to be applied on the base plate of a re-usable launcher. The system should combine lightness with good thermal resistance, along with a user-friendly application also on complex surfaces, that guarantees the structural integrity. The material should withstand the demanding conditions encountered during atmospheric reentry, which can reach a heat flux up to $360 \mathrm{~kW} /$ $\mathrm{m}^{2}$ in the base area of the launcher under investigation (RETALT1) [15].

For the purpose of testing the cork TPS in the VMK wind tunnel facility at DLR in Cologne, the material is applied to an inlay made from steal or Macor which is then fixed to the wind tunnel model. An image of the wind tunnel model with the TPS mounted to it, and a more detailed view on the TPS applied to the inlay, is shown in Fig. 2.
Two main systems were considered: sprayable and trowelable solutions. The sprayable solution is easier to apply on complex geometries; however, it has several issues related to the application process, such as porosity control, thickness control and mixture homogeneity. Moreover, the sprayable solution needs to consider many variables: projection pressure, flow rate, nozzle type and configuration, and therefore requires complex and specific equipment to be acquired. In addition, the toxic fumes released during spraying are an additional drawback [16-19].

A trowelable TPS solution, although more difficult to apply, also allows an in situ application, offering better control of mixture homogeneity and does not require any specific and complex equipment. For these reasons, the trowelable solution was the first approach selected since it offers the best compromise between advantages and disadvantages [8].

In this paper, a summary of the latest developments on this new TPS material is given including a discussion of the production process, characterization methods and main results obtained so far.

\section{Materials and methods}

The TPS development followed several iterative steps that are schematically represented in Fig. 3.

\subsection{Raw materials}

A trowelable TPS can be defined as a paste composed by a matrix resin and several fillers that give different properties to the final material. These fillers can be added with the objective of improving thermal properties and ablation, as well as to give structure to the matrix or rheological

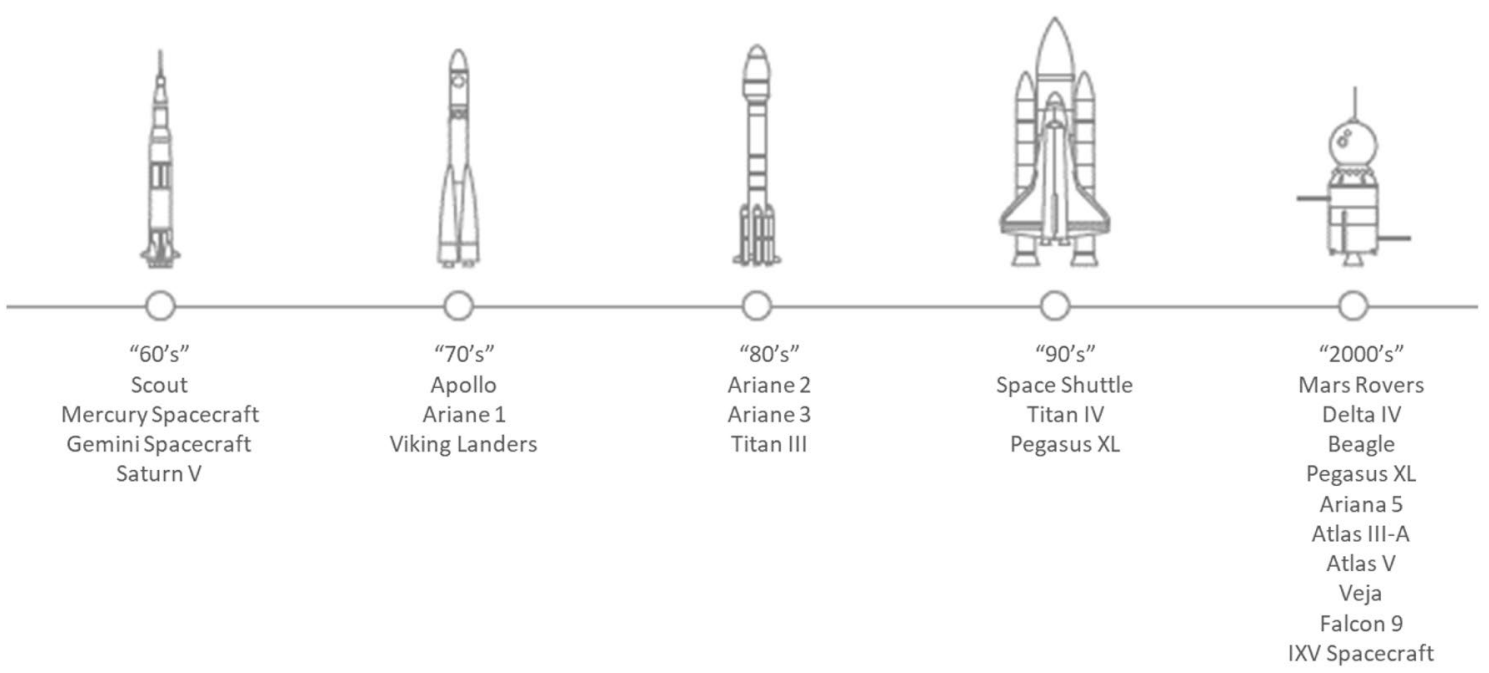

Fig. 1 Success records of cork TPS in aerospace 


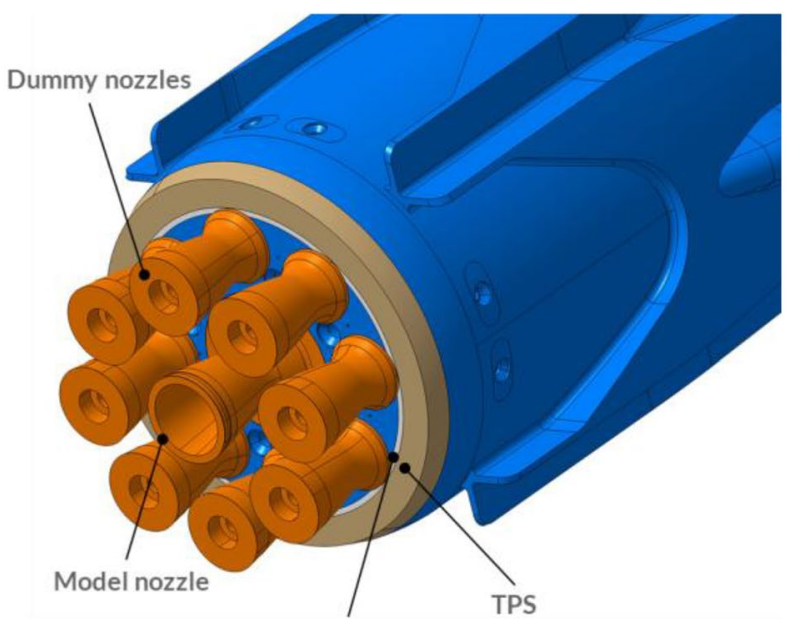

TPS-Inlay from Macor (Ceramics) or steal

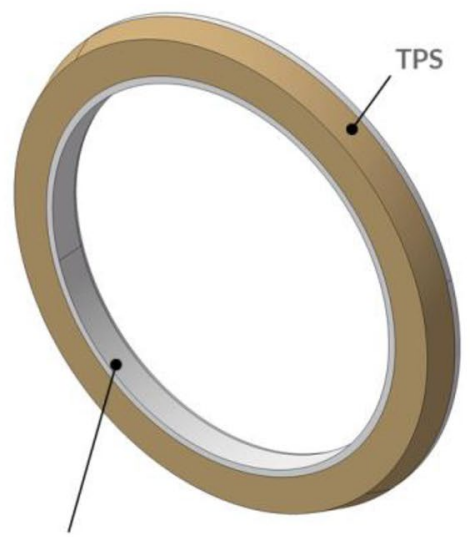

TPS-Inlay from

Macor (Ceramics) or steal

Fig. 2 Wind tunnel model with the TPS applied in situ to it (images from Ref. [20])

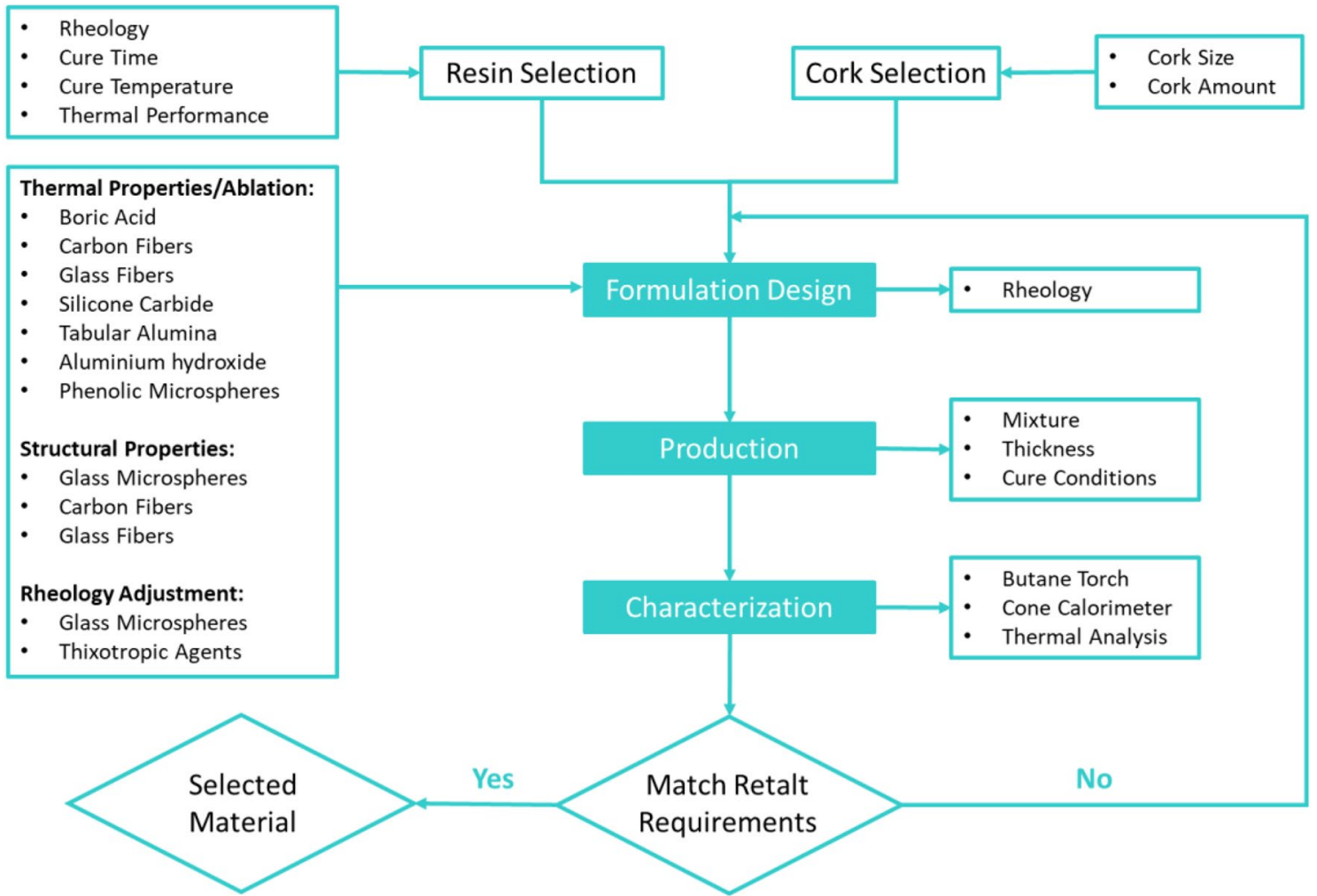

Fig. 3 Schematic representation of the work plan for the RETALT TPS design and manufacturing

adjustment to better application of the paste. The process of resin and filler additive selection is discussed below.

\section{Resin matrix}

During the development, several liquid resins were considered, namely polymeric MDI polyurethane, phenolic resole and two-component epoxy resin (Table 1). Gel time and temperature, solid content, viscosity and thermal properties of each resin, were taken into account during the selection process and epoxy resin was chosen as the best option, due to its good synergy with different fillers, good adhesion to different substrates and also curing process at room temperature. 
Table 1 Resins considered during the development of the new TPS

\begin{tabular}{lllll}
\hline & Density $\left(\mathrm{kg} / \mathrm{m}^{3}\right)$ & Viscosity $(\mathrm{mPa} \mathrm{s})$ & $\begin{array}{l}\text { Solid } \\
\text { content } \\
(\%)\end{array}$ & Gel time h:min (Temp) \\
\hline MDI polymeric polyurethane & 1180 & 1500 & 100 & - \\
Phenolic resole & 1240 & $450-600$ & 74 & $00: 20\left(130{ }^{\circ} \mathrm{C}\right)$ \\
Epoxy (2 components) & 1120 & 800 & 100 & $02: 25\left(20^{\circ} \mathrm{C}\right)$ \\
\hline
\end{tabular}

\section{Cork}

Cork is added in granule form, and it is considered the main component (in volume) of the final product. It plays a capital role regarding thermal insulation properties and its granule size and amount will impact the final performance. Two granule size distributions, between 0.2 and 0.5 and 0.5 and $1 \mathrm{~mm}$, were considered, with different quantities of incorporation, to find the best compromise between thermal performance and processability of the product. Smaller $0.2 / 0.5 \mathrm{~mm}$ granules are easy to process, both during mixing and application by trowelable technique, but tend to increase the density of the cured compound and to reduce flame resistance. On the other hand, $0.5 / 1 \mathrm{~mm}$ coarser granules show lower density cured material, better flame resistance while having enough processability. Higher amounts of cork should give better thermal performance (reducing thermal conductivity) but also reduces the capability of in situ application, due to a decreased flowability of the mixture.

\section{Fillers}

Fillers tested during the development can be divided into three main groups: thermal properties/ablation, structural properties, and rheological additives. Regarding the thermal performance, a material that withstands demanding conditions with creation of insulating char and flame retardancy is preferable. For that reason, fillers like boric acid, silicon carbide, tabular alumina, phenolic microspheres among others, were considered [7, 12]. Besides the thermal performance, structural properties also need to be assessed. The char formed during the burning process needs to give the best thermal protection possible to the virgin material behind it. For that, a surface without cracks and with good stiffness is desirable and, to achieve that, carbon fibers and glass microspheres give good final stability to the material and, in the case of the carbon fibers, additional carbon to the ablation and structure of the char. To avoid a separation of the liquid phase and the solid granules, a thixotropic agent is also needed to adjust the rheology of the paste.

\subsection{Mixing process}

The mixing process depends on the type of components. Each filler has its own processability issues and different resins led to different ways of processing it.
During the development, several optimizations were made regarding the mixing equipment. At first, a low-speed planetary mixer was used, allowing for a homogeneous mixture, but with the restrictions of a long mixing time and small quantities to be produced; only $100 \mathrm{~g}$ per batch. With the progress of the project, the need of having good dispersion of fillers (mainly fibers) and a perfect stoichiometry of the resin components led to the acquisition of a high shear disperser $(0.37 \mathrm{~kW}$ motor $400 \mathrm{~V}, 50 \mathrm{~Hz})$, with high velocity rotor (up to $3000 \mathrm{rpm}$ ) and user-friendly setup that has resulted in a much better final product. With this upgrade, the mixing capacity was increased to $300 \mathrm{~g}$ per batch.

The mixing process was started with the component $\mathrm{A}$ of the epoxy resin, together with the rheological additive, at a speed of $500 \mathrm{rpm}$ during $3 \mathrm{~min}$, in a glass jar of $500 \mathrm{~mL}$. Then carbon fibers and the remaining fillers (except cork) were added, and the rotation speed was kept at $500 \mathrm{rpm}$ for more than $10 \mathrm{~min}$. After this time, the rotor speed was reduced to $300 \mathrm{rpm}$, to add component $\mathrm{B}$ (hardener) of the epoxy resin (this reduction in speed is critical to reduce shear heat build-up that can lead to pre-cured resin, although the mixing jar was immersed in an iced water bath). After 2 min, the cork was added, and the mixture was finalized within 1-2 min.

To plan a future scale-up process, mixing should be kept under cooled condition, below gel temperature, and a slower hardener may be necessary to retard it.

\subsection{Application process}

The application process comprises several critical points that must be ensured to reach a final material with all the properties to what it was designed for.

Composition is the first point that has a great impact on the final application. Starting by the resin matrix, the best gel time needs to be found, as well as its curing conditions. With the challenge of developing an in-situ TPS material, curing at room temperature and as quickly as possible is desired. The epoxy system selected for the development comprises both the possibility of curing at room temperature, and a large gel time that allows a slow application, without the risk of precure. Gel time can be improved by a water bath technique or by changing the hardener for an extra slow one. Furthermore, just with a well-processed 
mixture, with the right amounts of thixotropic agents and expectable rheology, the material is able to be applied to the selected substrate, without the risk of running out from it.

Regarding the substrate, it must be analyzed and pretreated, according to its composition. If a metal substrate (aluminum or steel) will be used, both mechanical and chemical pre-treatments are needed, combining sanding with an epoxy primer application. If, on the other hand, a ceramic material is being used, grease cleaning with a solvent can be enough; however, an epoxy primer could be also applied. This step of substrate preparation will greatly reduce the probability of delamination of the material from the substrate, during burning tests.

Figure 4 shows the TPS paste (after mixing) being applied on a steel substrate, already pre-treated.

The trowelability of the TPS material, allows for a combination of different compositions, layer by layer, to reach a final material with different performing zones. With this rational, two different approaches were tested:

a) A single layer of material, composed by all the components of the formulation, having a $8-10 \mathrm{~mm}$ thickness

b) A two-layer material, the first layer with $8 \mathrm{~mm}$ mainly composed by cork together with some fillers, giving insulating properties and structure, and a top coating layer of $2 \mathrm{~mm}$ with fire retardants and raw materials with good thermal performance, two be directly exposed to the flame.

\subsection{Characterization}

The screening of the different materials regarding their flame behavior was made with butane torch tests followed by cone calorimeter tests. Finally, the most promising materials were characterized in terms of thermal

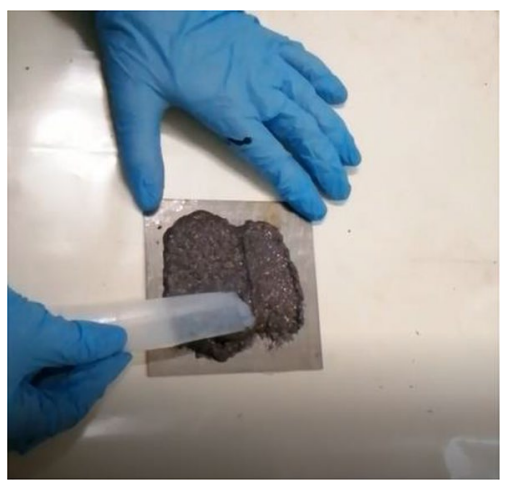

Fig. 4 Application of TPS paste on a steel substrate properties - thermal diffusivity, heat capacity and thermal conductivity.

The ultimate validation will be plasma tests at the arc heated facilities at DLR in Cologne, which are planned to be performed later in the RETALT project.

\subsubsection{Flame tests}

a) Butane torch

This first preliminary step was performed at the ACC laboratory, with $100 \times 100 \mathrm{~mm}$ samples with a thickness of 8-10 mm, which were exposed vertically to a butane torch (Fig. 5) with an approximate temperature of $1300{ }^{\circ} \mathrm{C}$. During the tests, the flame was always at approximately $50 \mathrm{~mm}$ distance from the material and focused in the center of the sample during a period of 4 $\min$.

The flame application is very localized on the samples but is sufficient to allow for surface appearance analyses before passing the material to the cone calorimeter test. The criteria to accept the material to the next stage are completely visual and qualitative, by observing the surface: if the material has no cracks, low or no intumescence and high char stiffness it proceeds to the cone calorimeter test with new samples made in the same conditions.

b) Cone calorimeter

A Cone calorimeter is a device to perform "reaction to fire" tests, according to ISO-5660-1 and can be used as trade off test for TPS materials as it was shown during the Aerofast Project [21]. Samples with $100 \times 100 \mathrm{~mm}$ width and $10 \mathrm{~mm}$ of thickness are exposed to $75 \mathrm{~kW} / \mathrm{m}^{2}$ of heat flux during 4 min (Fig. 6).

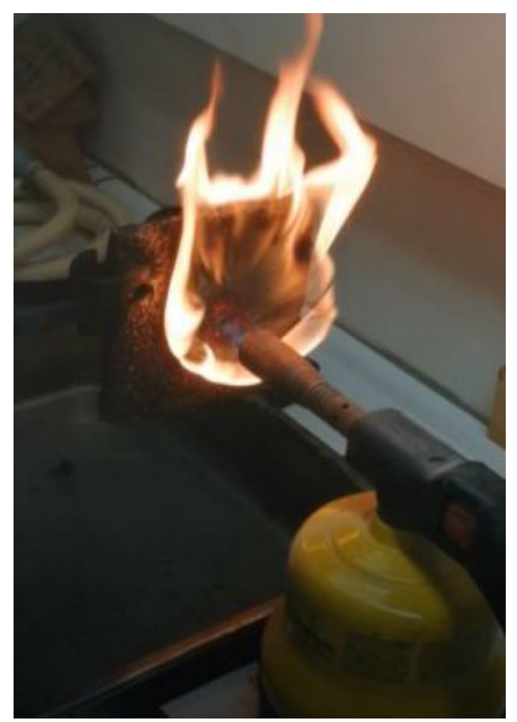

Fig. 5 Preliminary test with butane torch 


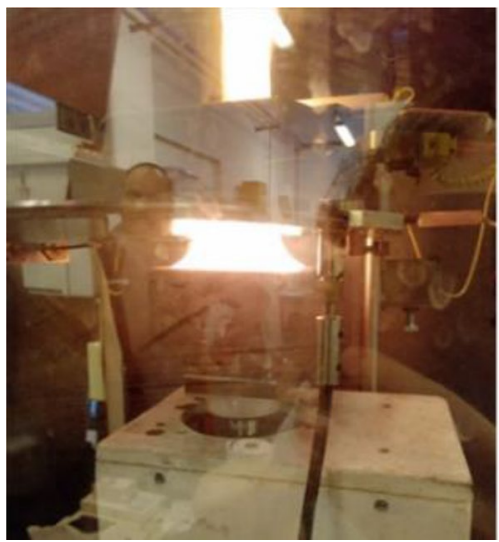

Fig. 6 Cone calorimeter test

Although the cone calorimeter gives other outputs like energy released during the burning process, $\mathrm{CO}_{2}$ and $\mathrm{CO}$ concentrations over the time, the main properties evaluated after the test were again surface appearance, intumescence and char stiffness. As the heat flux covers all the surface, unlike the butane torch, it gives a better indication of the real performance. Additionally, the quality of the adhesion to the substrate, influenced by the temperature and the contraction and expansion of the material is more realistic with cone calorimeter tests.

\subsubsection{Thermal properties}

Only materials with promising results underwent a set of thermal tests to define their intrinsic properties like specific heat, thermal diffusivity, thermal conductivity and thermogravimetric analysis. With that characterization, it is possible to establish the thermal properties of each material, which allows both the prediction of the best material to be used as TPS, and eventually what kind of optimizations need to be made in the formulation.

a. Specific heat, thermal diffusivity and thermal conductivity

By definition, the specific heat represents the amount of energy needed to raise one kilogram of material temperature by one Kelvin degree. Thermal diffusivity

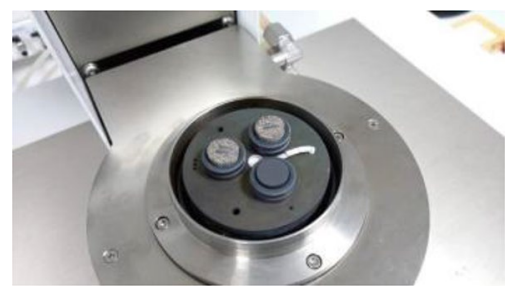

Fig. 7 Example of specific heat and thermal diffusivity determination in Netzsch LFA 457 Microflash

measures the heat transfer rate from one side to another in a material [22].

These properties are determined based on ASTM E 1461 in Netzsch LFA 457 Microflash with Pyroceram 9606 as reference material between 25 and $300{ }^{\circ} \mathrm{C}$, with cylindrical samples of $12.6 \mathrm{~mm}$ of diameter and $2.5 \mathrm{~mm}$ of height (Fig. 7). Two samples of each material were tested and an average result was given.

"Thermal conductivity can be defined as the rate at which heat is transferred by conduction through a unit cross-sectional area of a material when a temperature gradient exits perpendicular to the area" [22]. It is indirectly obtained by Eq. (1), after the determination of the specific heat, the thermal diffusivity and the known density, which is computed by measuring the mass with a microbalance and the volume with a regular accurate dimensional control [22].

$\lambda(T)=a(T) \cdot c p(T) \cdot f(T)$,

$\lambda, a, c p$ and $f$ represent thermal conductivity, thermal diffusivity, specific heat and density, respectively.

b. Thermogravimetric analysis

To determine how TPS decomposes with temperature, a thermogravimetric analysis (TGA) was performed in a STA 7200 RV Hitachi, from SCANSCI, to measure the mass loss history of the pyrolyzed cork as a function of temperature, considering two different procedures, detailed in Table 2. Sample mass should be between 8 and $13 \mathrm{mg}$ [1].
Table 2 TGA implemented method

\begin{tabular}{llllll}
\hline Procedure & Temp. range $\left({ }^{\circ} \mathrm{C}\right)$ & $\begin{array}{l}\text { Temp. rate } \\
\left({ }^{\circ} \mathrm{C} / \mathrm{min}\right)\end{array}$ & Atmosphere & $\begin{array}{l}\text { Flow rate } \\
(\mathrm{mL} / \mathrm{min})\end{array}$ & Pan \\
\hline 1 & $25-1000$ & 10 & Nitrogen & 200 & Platinum \\
2 & $25-600$ & 10 & Nitrogen & 200 & Platinum \\
& $600-1000$ & 10 & Nitrogen + oxygen & $200 / 40$ & Platinum \\
\hline
\end{tabular}




\section{Results and discussion}

Throughout the characterization process, the results from the flame tests and the thermal property characterizations were combined and analyzed, to select the formulation that best fits the RETALT requirements.

Single layer approach-cone calorimeter flame test

As discussed, these flame tests were made to evaluate thermal behavior, namely the cracks avoidance and mass loss reduction. Table 3 presents results of several samples and shows the evolution and improvement of the material during the development process. As described previously, materials were applied in thicknesses between 8 and $10 \mathrm{~mm}$, on ceramic and metallic substrates, which were previously prepared and tested according to Sects. 2.3 and 2.4.1b in "Materials and methods". The evaluation criteria focused mainly on visual aspects, such as surface appearance and char stiffness, and are detailed below:

Cracks

The existence/inexistence of cracks is the first parameter evaluated.

In such type of material, exposed to demanding temperatures during flights, a single crack potentiates the heat transfer to the interior surface, reducing the insulation performance of the material. For this reason, samples that showed surface cracks were excluded.

Surface stiffness and intumescence

Stiffer char surface ensures the material to withstand higher shear forces, present in descent trajectories. In that way, intumescence behavior should be avoided because material expansion during the burning phase increases porosity and the surface structure gets weak.

Material consumption-The final criterion evaluated is the material consumption that can be seen by the thickness of the material that remained intact during burning test.

From Table 1, it can be seen that the TPS01, composed just by cork agglomerated with epoxy resin, suffered almost full consumption of the material after the cone calorimeter test, in parallel with a weak surface. The inclusion of phenolic microspheres (TPS02) helped to keep more quantity of material intact but some cracks on the surface remained. To improve that the phenolic microspheres were substituted by glass microspheres (TPS03) which helped to keep a wellstructured surface. However, further improvements occurred when glass microspheres were replaced by a combination

Table 3 Cone calorimeter result evolution during the RETALT project

\begin{tabular}{|c|c|c|c|c|}
\hline Ref. & Composition & Obs. & $\begin{array}{c}\text { Mass Loss } \\
(\%)\end{array}$ & Final appearanc \\
\hline TPS01 & $\begin{array}{l}\text { Epoxy resin and } \\
\text { cork }\end{array}$ & $\begin{array}{l}\text { Some intumescence and } \\
\text { weak surface. } \\
\text { Almost full consumption of the } \\
\text { material. }\end{array}$ & 93,4 & \\
\hline TPS02 & $\begin{array}{l}\text { Epoxy resin, cork } \\
\text { and phenolic } \\
\text { microspheres }\end{array}$ & $\begin{array}{c}\text { Some cracks. } \\
\text { Some intumescence but stiffer } \\
\text { surface. } \\
\text { High degradation of the material. }\end{array}$ & 61,2 & \\
\hline TPS03 & $\begin{array}{l}\text { Epoxy resin, cork } \\
\text { and glass } \\
\text { microspheres }\end{array}$ & $\begin{array}{c}\text { Almost no cracks } \\
\text { Some intumescence but } \\
\text { stiffer surface. } \\
\text { High degradation of the material. }\end{array}$ & 42,4 & \\
\hline TPS04 & $\begin{array}{l}\text { Epoxy resin, } \\
\text { cork, boric acid and } \\
\text { carbon fibers }\end{array}$ & $\begin{array}{c}\text { No cracks. } \\
\text { High intumescence but } \\
\text { stiff surface. } \\
\text { Lower degradation. }\end{array}$ & 34,0 & \\
\hline TPS05 & $\begin{array}{l}\text { TPS04 with } \\
\text { rheological } \\
\text { adjustment. }\end{array}$ & $\begin{array}{c}\text { No Cracks. } \\
\text { Stiff surface. } \\
\text { Lower degradation. }\end{array}$ & 32,3 & \\
\hline
\end{tabular}




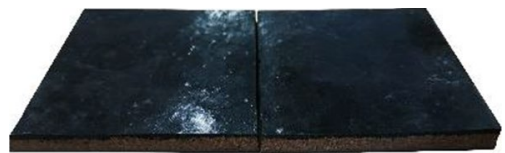

Fig. 8 Coated samples before cone calorimeter test

of carbon fibers and boric acid (TPS04). This allowed the material to have better surface appearance, combining surface stiffness with cracks avoidance and the boric acid gave an additional self-extinguishing to the material. Finally, the current formulation (TPS05), similar to the previous one (TPS04) but with the addition of a thixotropic agent, allowed the paste to be spreadable with a spatula, while keeping the surface appearance after burning test.

\section{Two-layer approach-cone calorimeter flame test}

During the development process, the possibility of combining two different formulation layers was evaluated. A first layer with $8 \mathrm{~mm}$, rich in cork to give insulation properties, and another $2 \mathrm{~mm}$ layer above that, rich in carbon fibers and boric acid to provide the required thermal properties, represented in Fig. 8. The second layer was applied above the first one, without any pre-treatment of the surface nor application of a primer, as both layers are composed by epoxy resin.

Different combinations of materials were used with the two-layer configuration approach, and the results are presented in Table 4.
The objective to keep the insulation layer intact during the test performance was achieved. However, the final surface was as good as TPS03, TPS04 or TPS05 with the cork materials without any coating. This fact, added by the risk of delamination due to the two layers, led to discarding of this approach.

\section{Substrate adhesion}

To evaluate the adhesion of the material, different substrates were tested, ceramics (and Macor), steel and aluminum.

During the cone calorimeter tests, the incident heat flux on the material covers the entire surface, which can lead to thermal expansions or contractions of the material, and consequently delamination from the substrate. This problem is more frequently on steel substrates, as ceramics have some porosity that helps the impregnation and consequently adhesion of the TPS to the substrate.

To avoid this issue, a pre-treatment needs to be done on the substrate before the application of the TPS. For that, an epoxy primer was applied to promote chemical adhesion during the characterization tests. In Fig. 9, two examples of samples applied on aluminum substrate are represented, one of them without any pre-treatment, and consequently with delamination, and the other one where the primer was applied, and no delamination was observed.

Table 4 Surface appearance of coated samples after cone calorimeter test

Ref.

Composition

Base layer: Cork and boric acid

Top Layer: Carbon Fibers and Boric Acid

TPSB
Base Layer: Cork, boric acid and carbon fibers

Top Layer: Carbon fibers and boric acid
Obs.

Final appearance

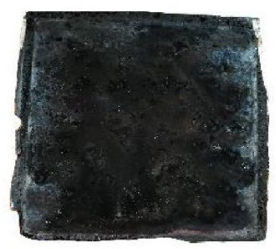

High intumescence. Stiff surface. Only consumption of top layer. No cracks.

Surface is not smooth, with small $3 \mathrm{~mm}$ bubbles.

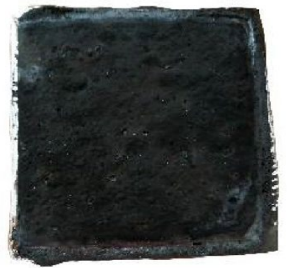

Fig. 9 TPS material delaminated from the substrate (left) and material pre-treated with epoxy primer, without delamination from the substrate (right) after cone calorimeter test
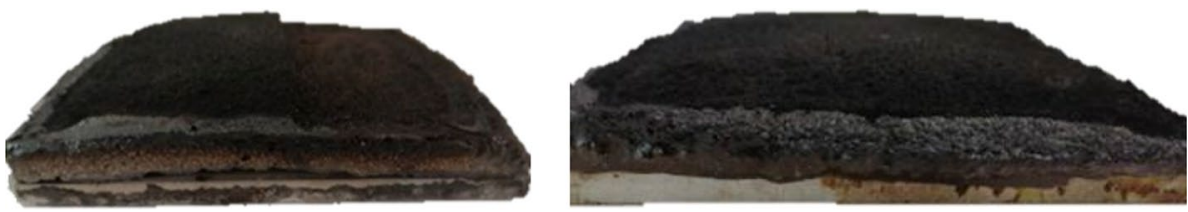
Table 5 Thermal properties of P50 and new materials developed, at $25^{\circ} \mathrm{C}$

\begin{tabular}{|c|c|c|c|c|c|}
\hline \multirow[b]{2}{*}{ P50 } & \multirow{2}{*}{$\begin{array}{l}\begin{array}{l}\text { Density } \\
\left(\mathrm{kg} / \mathrm{m}^{3}\right)\end{array} \\
460\end{array}$} & \multicolumn{2}{|c|}{$\begin{array}{l}\text { Thermal } \\
\text { conductivity } \\
(\mathrm{W} / \mathrm{m} \mathrm{K})\end{array}$} & \multirow[t]{2}{*}{$\begin{array}{l}\text { Specific heat } \\
(\mathrm{J} / \mathrm{g} \mathrm{K})\end{array}$} & \multirow{2}{*}{ 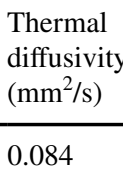 } \\
\hline & & 0.062 & 1.61 & & \\
\hline TPS04 & 634 & 0.092 & 1.02 & & 0.143 \\
\hline TPS05 & 715 & 0.25 & 2.55 & & 0.137 \\
\hline
\end{tabular}

\section{Thermal properties}

Concerning the thermal properties, the results of thermal conductivity, specific heat and thermal diffusivity are summarized in Table 5.

From Table 5, it is possible to conclude that the thermal conductivity is substantially higher when comparing P50 with the new materials developed. TPS04 has a better thermal performance than TPS05, however, its rheology and amounts of cork do not allow an easy application of the material. The value of the thermal conductivity is higher for TPS05 due to a decrease in the amount of cork, imperative for the rheological adjustment. This change also has an impact on the density.

Regarding the thermogravimetric analysis, two different tests with both P50 and TPS05 material were performed: one up to $1000{ }^{\circ} \mathrm{C}$ in a nitrogen atmosphere and a second one where from 600 to $1000{ }^{\circ} \mathrm{C}$ oxygen was added. The results are presented in Fig. 10.

From these results and as it was expected, until $600{ }^{\circ} \mathrm{C}$, P50 start losing mass at lower temperatures than TPS05. At higher temperatures, the materials exposed to oxidative atmosphere have shown that P50 has full pyrolysis while TPSO5 has around $10 \%$ remaining mass due to mineral residue. Furthermore, it is possible to observe that P50 has shown higher levels of pyrolysis at lower temperatures than TPS05, which is a result of the much higher amount of cork in the formulation.

Finally, comparing the samples from the cone calorimeter of P50 with TPS04 and TPS05 in Fig. 11, it is possible to conclude that the latter has significant improvements on the char surface, with no cracks, and a better stiffness.
Fig. 10 Thermogravimetric analysis of P50 and TPS05 with $\mathrm{N}_{2}$ and $\mathrm{N}_{2} / \mathrm{O}_{2}$ atmosphere
Fig. 11 Current ACC TPSP50 and new TPS materials (TPS04 and TPS05), after cone calorimeter tests

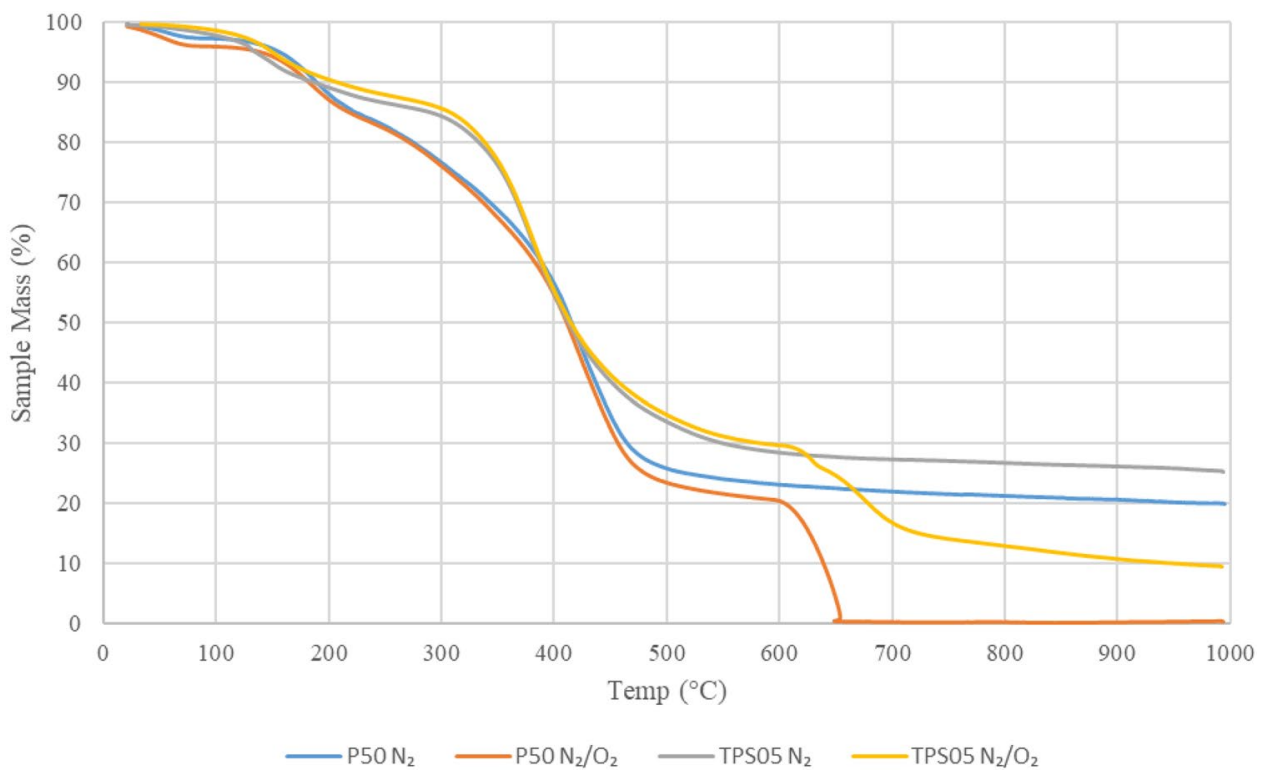

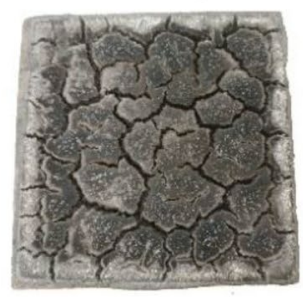

P50

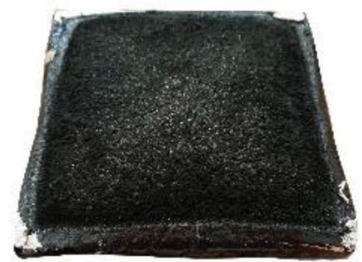

TPS04

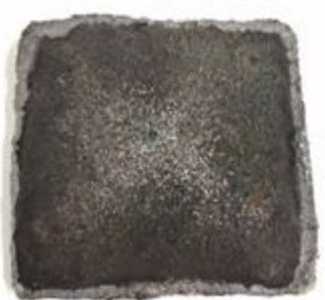

TPS05 


\section{Conclusions}

The development of a new TPS material, combining cork with epoxy resin and additives in a form of a paste, requires a careful selection of the different compositions and a detailed analysis of the impacts of each type of component on the final performance. Characterization processes cover butane torch, cone calorimeter and thermal properties like thermal conductivity, specific heat and thermal diffusivity as first trade-off process.

The last developments made by ACC in the aerospace field comprises a new material, capable of being applied in situ by trowelability, and that presents good fire behavior as well as insulating properties. The new TPS material allowed to avoid surface cracks during fire exposure, as well as keep a stiff and well-structured char surface after that.

Although it is still at a low TRL, these promising results suggest a possibility of having a material adjustable to complex shapes, with easy application and room temperature cure. To test the material at high thermal heat loads in a representative environment at a later state in the RETALT project, sample tests are foreseen in the arc-heated facilities at the Supersonic and Hypersonic Technologies Department of DLR in Cologne.

By comparison with other cork materials, made by agglomeration process and already commercialized by ACC, this new material has the advantage of avoiding the surface cracks and to facilitate its application in complex zones.

Acknowledgements The RETALT project has received funding from the European Union's Horizon 2020 research and innovation framework program under grant agreement No 821890.

Open Access This article is licensed under a Creative Commons Attribution 4.0 International License, which permits use, sharing, adaptation, distribution and reproduction in any medium or format, as long as you give appropriate credit to the original author(s) and the source, provide a link to the Creative Commons licence, and indicate if changes were made. The images or other third party material in this article are included in the article's Creative Commons licence, unless indicated otherwise in a credit line to the material. If material is not included in the article's Creative Commons licence and your intended use is not permitted by statutory regulation or exceeds the permitted use, you will need to obtain permission directly from the copyright holder. To view a copy of this licence, visit http://creativecommons.org/licenses/by/4.0/.

\section{References}

1. Davis, D.: Fundamentals of launch vehicle ablative thermal protection system (TPS) materials. https://ntrs.nasa.gov/citations/ 20170009022 (2017). Accessed 2021

2. Duffa, G.: Ablative thermal protection systems modeling, pp. 9-13. AIAA Education Series (2013)
3. Uyanna, O., Najafi, H.: Thermal protection systems for space vehicles: a review on technology development, current challenges and future prospects. Acta Astronaut. 176, 341-356 (2020)

4. Effie, G.: Thermal protection and control: internship report, pp. 1-8. University Lincoln Nebraska (2013)

5. Stackpoole, M., Ghandehari, E., Covington, J.T.M.: Flexible ablators. Patent US 9,592,923 B1, 14 March (2017)

6. Dunn, B.D.: Materials and processes: for spacecraft and high reliability applications, pp. 1-53. Springer (2015)

7. Sommer, J.G., Falls, C.: Ablative insulation prepared from epoxy resin, a polysulfide and boric acid. Patent 3,457,215, 22 July (1969)

8. Headrick, S.E., Hill, R.L.: Trowelable ablative coating composition and method of use. Patent US4772495A, 6 June (1989)

9. Boghozian, T., Stackpole, M., Gonzales, G., Wong, G.J.: Alternative high performance polymers for ablative thermal protection systems. In: ID: 20160004673, Presentation in ACS 249th National Meeting and Exposition, NASA

10. Pereira, H.: Cork: biology, production and uses, 1st edn., pp. 33-55. Elsevier, Amsterdam (2007)

11. Drescher, O., Hörschgen-Eggers, M., Pinaud, G., Podeur, P.M.: Cork based thermal protection system for sounding rocket applications-development and flight testing. In: 23rd ESA PAC symposium (2017)

12. Pelin, G., Pelin, C.-E., Stefan, A., Dinca, I., Andronescu, E., Oprea, O., Ficai, D., Trusca, R.: Development and properties of advanced composites based on cork and nanometric silicon carbide-filled phenolic resin. Bull. Mater. Sci. 41(1), 1-9 (2018)

13. Cosby, S.A., Kelly, M., Waveren, B.V.: Silicone cork ablative material. Patent US 6,933,334 B2, 23 August (2005)

14. Strauss, E.L.: Low density ablator compositions. Patent 4,031,059, 28 January (1976)

15. Laureti, M., Karl, S.: Aerothermal databases and load predictions. RETALT Internal Report, p. 15. Göttingen, Germany (2020)

16. Reimer, T., Zuber, C., Seiler, H., Milow, B., Gülhan, A., Esser, B.: Development and testing of spray on thermal protection system materials based on cork and aerogels. In: 8th European conference for Aeronautics and Space Sciences (EUCASS)

17. Patel, K., Meeks, C.: Development of a convergent spray technologies spray process for a solventless sprayable coating, MCC-1, ID: 19990008827, NASA. Kenedy Space Center, Florida (1998)

18. Scarpa, J.G., Marlin, J.D., Hall, T., Snyder, J.D.: Convergent spray nozzle shut-down system. Patent 6,322,000 B1, 27 November (2001)

19. Simpson, W.G., Sharpe, M.H., Hill, W.E.: Sprayable lightweight ablative coating. Patent 5,064,868, 12 November (1991)

20. Kirchheck, M.D.: Wind tunnel models for VMK tests (DLR). RETALT Internal Report, Cologne, Germany (2020)

21. Pinaudy, G., Eekelen, A., Bouillyy, J.M.: Aerofast: development of cork TPS material and a 3D comparative thermal/ablation analysis of an appolo and biconic sled shape for an aerocapture mission. In: 8th International probe workshop, June 6-10, Portsmouth-USA, p. 13 (2011)

22. Incropera, F.P., Dewitt, D.P., Bergman, T.L., Lavine, A.S.: Fundamentals of heat and mass transfer, pp. 60-70. Wiley, Hoboken (2007)

Publisher's Note Springer Nature remains neutral with regard to jurisdictional claims in published maps and institutional affiliations. 